\title{
Suitability Analysis of Water Pan Sites for Pastoralists: A Case Study of Kajiado County in Kenya
}

\author{
Christine Mutua, Mark Boitt \\ Department of Geomatics Engineering and Geospatial Information System Name of Organization, \\ Jomo Kenyatta University of Agriculture and Technology, Kenya
}

Copyright $(2017$ by authors, all rights reserved. Authors agree that this article remains permanently open access under the terms of the Creative Commons Attribution License 4.0 International License

\begin{abstract}
The paper looks into the analysis of water spatial accessibility by pastoralists in Kajiado County. Since it's a pastoralist area, the demand for water is essential, but due to climate change, the area experiences erratic rains, extreme temperatures and cyclic and prolonged droughts. The need to access improved water supply is considered to boost economic development poverty alleviation. With inadequate water harvesting structures, integrated journal positions the need to excavate more water pans which require a systematic study to come up with the suitable positions where excavation will occur. To come up with a commendable finding and analysis, the paper gives a methodology for data collection identifying relevant factors affecting citing of water. The factors incorporated in questionnaires were slope, soils, location of pastures, villages, existing water points and grazing routes. Therefore, both critical and descriptive discussion of the field's issues is warranted. From the suitability analysis, of the county's land mass $3.06 \%$ is in very highly suitable, $28.67 \%$ is highly suitable, $67.98 \%$ is moderately suitable and $0.29 \%$ is not suitable. The comparative analysis shows that the new water pans are established in moderately suitable area. The study concludes by crediting the need to attributed GIS analysis and spatial modeling for the purpose of helping the County Government effort to provide sustainable water pans to its people.
\end{abstract}

Keywords Pastoralists, Spatial Accessibility, Suitability Map, Water Pans, Kajiado County

\section{Introduction}

Water is a precious natural resource important for life,

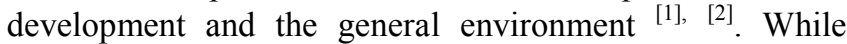
access to safe water is a human right, globally, 768 million people remain without access to an improved source of water. It is estimated by 2050 , the global demand for water will increase by $50 \%$ with the highest demand in developing economies countries ${ }^{[3]}$.

Approximately $80 \%$ of Kenya's land area is arid or semi-arid (ASAL), and only $20 \%$ is arable. These ASAL areas host about $35 \%$ of Kenya's population ${ }^{[4]}$. Due to this, Kenya is classified as a chronically water-scarce country and is vulnerable due to water insecurity caused by erratic rainfall patterns and the influence of climate change ${ }^{[5]}$.

Kajiado, a county in Kenya, relies on pastoralism as the main source of livelihood to majority of rural households. The County is categorized as a water scarce county ${ }^{[6]}$. Most of the sources of water are seasonal hence not reliable and the available ground water contains high salt levels in some parts. The demand for fresh water is high with people traveling an average distance $10 \mathrm{Km}$ from the homesteads to access the water ${ }^{[7]}$. Access to natural resources such as water and pastures is essential for sustainable poverty reduction. The livelihoods of rural people without access, or with very limited access to such resources are vulnerable ${ }^{[8]}$. Access to the improved water supply is considered to boost economic development poverty alleviation ${ }^{[9]}$.

Due to climate change, erratic rains, extreme temperatures and cyclic and prolonged droughts are experienced in Kajiado County. This has resulted in a decrease in the pasture for livestock, wildlife and domestic use thus leading to serious resource conflict. The local pastoral communities are forced to adjust to climate variability by maintaining mobility and walking for long distances as they respond to spatial and time-related weather changes ${ }^{[7]}$. In this case, the county has integrated plan sites which include the sinking of more boreholes and excavation of more water pans. Being a semi-arid county, there is an uneven distribution of the water points, unreliable rainfall, and inadequate water sources. This requires a systematic study to come up with the suitable locations where sinking and excavation will occur by determining the current situation regarding accessibility.

The main objective of this research is to carry out a suitability analysis using multi-criteria method to determine the suitable areas to locate water pans within Kajiado County

The specific objectives include: a) Assess and develop set of criteria and factors to locate suitable water pans, b) 
Weighing the variables taking an importance to placing suitableness water pans, c) Assessing the suitability of the new water pans within the county dug in the year 2015 .

\subsection{Study Area}

The study area is Kajiado County located in the southern part of Kenya with area coverage of 21,900.9 square kilometres. Administratively, it is divided into 5 sub-counties, 17 divisions, and 105 locations. In 2009 the county had a population of 687,312 , with an annual growth rate of $5.5 \%$ with a population in 2015 estimated to be 898,289 with most people living in rural areas. In 2012 it was projected that 23.8 percent of the total population were in urban areas ${ }^{[7]}$. Fig. 1 below is a map showing Kajiado County.

\section{Literature Review}

\subsection{Water and Pastoralism in Kajiado County}

Pastoralists are people whose lively-hood depends mainly on the raising of domestic animals including cattle, camels, goats, sheep and donkeys, which are used for milk, meat, transport, and trade and mainly occupy savannah, semi-arid, or arid deserts where rain-fed agriculture is precarious ${ }^{[10]}$. Pastoralism is a mode of livelihood in which $50 \%$ or more of household gross revenue comes from livestock or livestock related activities ${ }^{[11]}$.

To be practiced effectively, pastoralism depends on freedom of movement for all herds between pastures and water sources. Pastoralism is well adapted to coping with a single rain failure in a particular area, but when successive rainy seasons fail there is simply insufficient regeneration of grazing land and pasture shrinks ${ }^{[12]}$

In Kajiado County, local pastoral communities are forced to adjust to climate variability by maintaining mobility and walking for long distances in search of water and pasture. The average distance covered by livestock has been increasing as a result of drying up of temporary water sources during dry spells ${ }^{[6]}$. The county's uneven distribution of water points, unreliable rainfall, and inadequate water sources are the major contributing factors [7]. The effect of this is livestock emaciation resulting in reduced household food security ${ }^{[13]}$. Between December 2014 and January 2014 the average milk production decreased from 2.37 litres to 1.88 litres per household per day from livestock emaciation ${ }^{[14]}$.

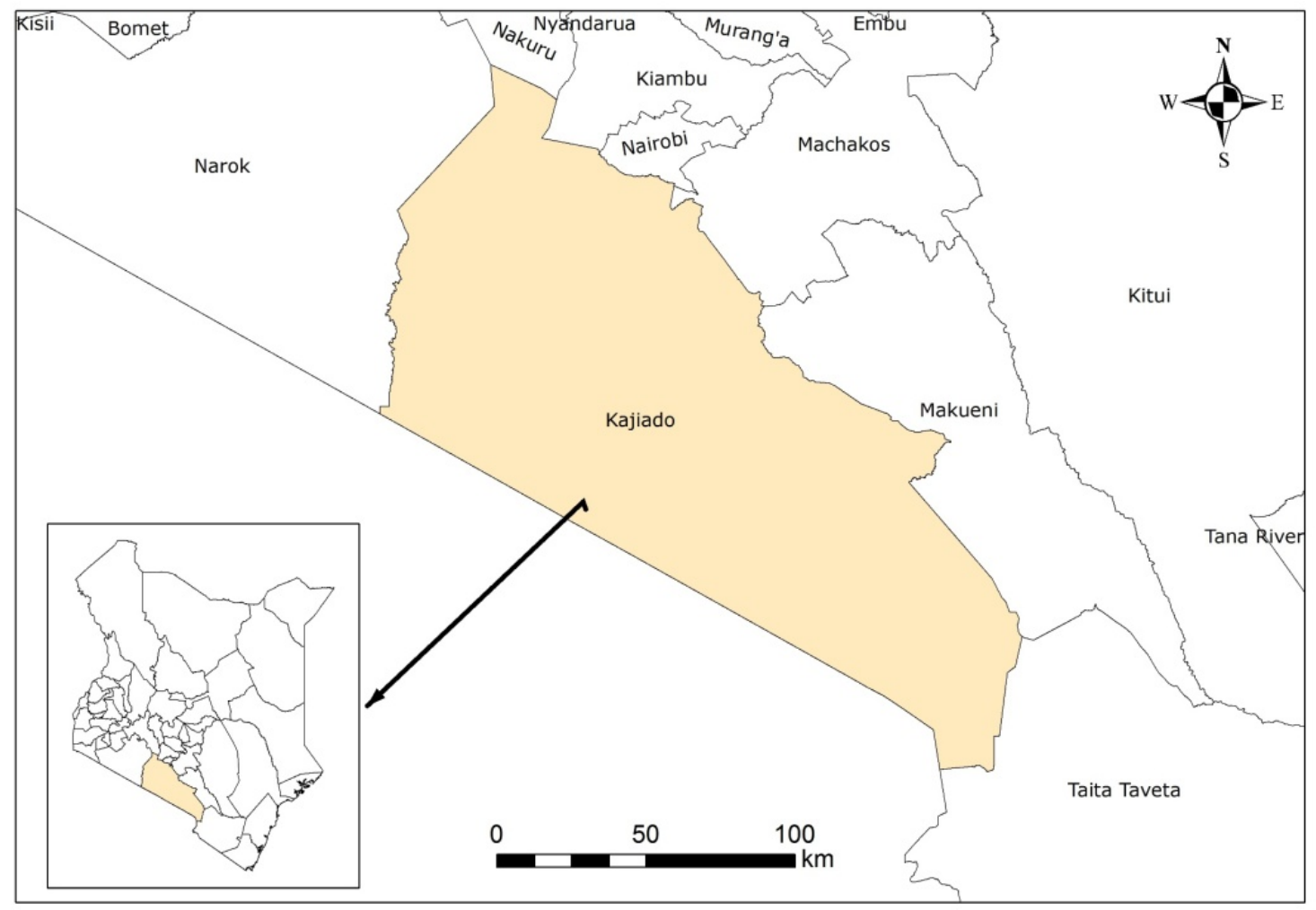

Figure 1. Study area, Kajiado County 


\subsection{Selection of Water Pan Site}

Site selection has traditionally been based on economic and technical criteria. In such analysis, selection criteria have to satisfy some social and environmental requirements, which are enforced by legislations ${ }^{[15]}$. Where there is a lack of planning in water point's selection, the water points have been unsuccessful.

Site selection involves finding locations that satisfy a set of criteria ${ }^{[16]},{ }^{[17]}$. It is done by evaluating each location's suitability using weights. The assignment of the weights can be estimated by expert opinion. GIS capabilities such as data storage and organization, spatial analysis, visualization and query which make it suited for this analysis ${ }^{[16]},{ }^{[18]}$. For early planning phases, the spatial multi-criteria analysis provides procedures to structure decision problems while GIS plays a role in analyzing spatial data ${ }^{[9]}$.

\subsection{Criteria for Selecting a Water Point}

Informed siting of a water source is the basis of its success and long-term sustainability. This task of siting requires consideration of several interrelated factors ${ }^{[19]}$. The following factors majorly affect rainwater harvesting using water pans:

Soil; places with deep clay/silt soils (fine textured soils) are the best sites for excavating water pans. Coarse textured sandy soils are highly permeable, and water will drain through them easily thus should be avoided ${ }^{[20]}$.

Proximity to the point of use from villages and grazing; within the constraints of geology, water resources should ideally be sited as close as possible to the point of use ${ }^{[19]}$.

Proximity to existing water pans; in areas where some water point exist, new water pans should be sited further away ${ }^{[21]}$.

Slope; General topography of the area should be slanting gently to allow the flow of water into the pan. The land surface should be fairly flat. Ideally, areas with steep slopes are considered unsuitable.

Urban areas; water access in urban centers is better than in rural areas because of high water connectivity by the service provider. However, pastoralism does not occur in urban areas. Therefore urban areas are excluded in the study ${ }^{[7]}$.

\subsection{Weighting}

Multi-Criteria Analysis problems often involve criteria of varying importance; therefore, information about the relative importance of the criteria is needed. This is achieved by assigning a weight to each criterion ${ }^{[9]}$.

The AHP generates a weight for each evaluation criterion according to the decision maker's pairwise comparisons of the criteria. AHP combines the criteria weights and the options scores, thus determining a global score for each option, and a consequent ranking. The global score for a given option is a weighted sum of the scores it obtained on all the criteria ${ }^{[22]}$.

Saaty et al., ${ }^{[22]}$ observes that engaging experts in decision making should not be random. The investigator needs to know and the judge selected should have both knowledge and practical experience with the matter being investigated. Therefore one expert judge may suffice unless political expediency requires that several judges from different constituencies are necessary ${ }^{[23]}$. In the research, responses should be sought from diverse groups of experts, having the expertise required in the application domain, with each group having several respondents ${ }^{[23]}$.

\subsection{Normalized Difference Vegetation Index (NDVI)}

Pastures being an essential element in this study, determining the condition of pastures can be done using the Normalized Difference Vegetative Index (NDVI) ratio. NDVI has been related to nitrogen status, chlorophyll content, green leaf biomass, and grain yield ${ }^{[24]}$

NDVI is calculated from these individual measurements as follows:

$$
N D V I=(N I R-R e d) /(N I R+R e d) \quad \text { Equation } 1
$$

Where Red and NIR in equation (1), stand for the spectral reflectance measurements acquired in the red and near-infrared regions, respectively. NDVI itself thus varies between -1.0 and +1.0 .

NDVI of vegetation canopy will lead to positive values. Clouds and snow fields will be characterized by negative values of this index. Free standing water (e.g., oceans, seas, lakes, and rivers) which have a rather low reflectance in both spectral bands and thus result in very low positive or even slightly negative NDVI values. Soils exhibit a near-infrared spectral reflectance somewhat larger than the red and thus tend to also generate rather small positive NDVI values $(0.1$ to 0.2). Very low values of NDVI ( 0.1 and below) correspond to barren areas of rock, sand, or snow. Moderate values represent shrub and grassland $(0.2$ to 0.3$)$. High values indicate temperate and tropical rainforests $(0.6$ to 0.8$)$ [25].

\section{Methodology}

The methodology followed in the study has been summarized as in Fig. 2 below; 


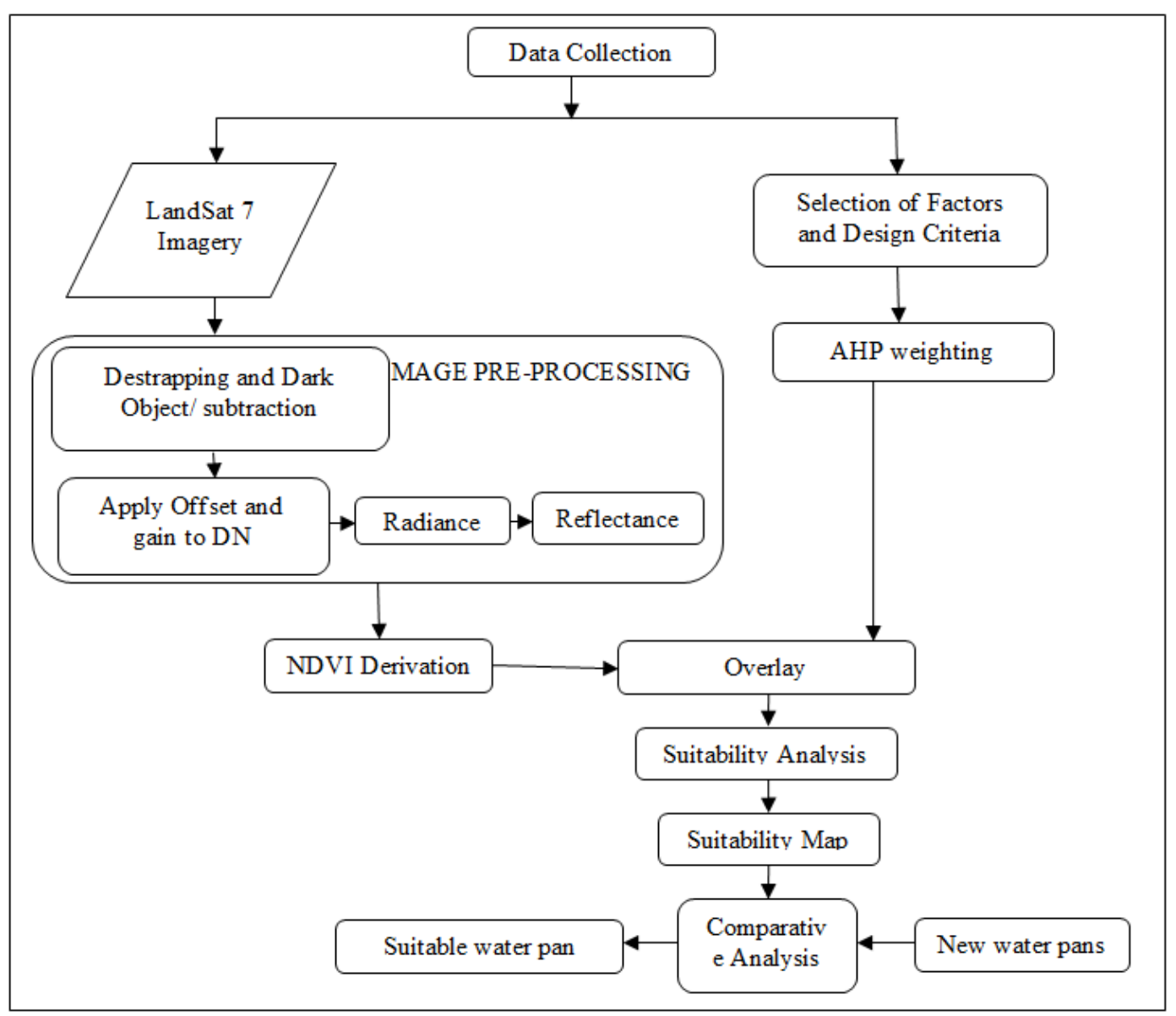

Figure 2. Study Methodology

\subsection{Data Sources}

Table 1. Data sources

\begin{tabular}{|c|c|c|c|}
\hline DATA & SOURCE & YEAR & RESOLUTION \\
\hline Landsat Image & Glovis & $19995,2005,2015$ & $30 \mathrm{~m}$ \\
\hline Grazing Routes & $\begin{array}{c}\text { WeltHunger Life, European } \\
\text { Commission Humanitarian Aid }\end{array}$ & 2011 & County Level \\
\hline Villages & $\begin{array}{c}\text { ILRI, Almanac Characterization Tool } \\
\text { (ACT) database }\end{array}$ & 2010 & $30 \mathrm{~m}$ \\
\hline Digital Elevation Model (DEM) & Aster Website & \\
\hline Existing water points & $\begin{array}{c}\text { ERMIS Africa, Tana Athi Services } \\
\text { Board, Netherlands Development } \\
\text { Organization }\end{array}$ & \begin{tabular}{c} 
County Level \\
\hline Soils
\end{tabular} & $\begin{array}{c}\text { ILRI (International Livestock Research } \\
\text { Institute) }\end{array}$ \\
\hline Agricultural Area & WRI (World Research Institute & 2007 & Kajiado County \\
\hline
\end{tabular}

\subsection{AHP Weighting}

The identified relevant factors affecting siting of water were; slope, soils and location of pastures, villages, existing water points and grazing routes and these were incorporated in questionnaires. Experts who formed part of the respondents were surveyors, Land use planners, county administrators, pastoralist, environmentalists and water officers from Kajiado County.

Experts were approached at workplaces to avoid inconvenience, encourage participation and with no compensation ${ }^{[23]}{ }^{[26]}$. Participation was voluntary and took place from July 2015 to March 2016. The experts compared two factors at a time and indicated which had more influence on a scale of 1-9.

\subsection{Selection of the Best Sites}

The variables involved were classified into four categories: very highly suitable $(\mathrm{H} 1)$, highly suitable $(\mathrm{H} 2)$, moderately suitable (H3) and not suitable (H4). 
Table 2. Study criteria for the variables

\begin{tabular}{|c|c|c|}
\hline Data & Source & Source \\
\hline Slope & $\begin{array}{c}\text { H1 -0-2\% Flat } \\
\text { H2- 2-8\% Undulating } \\
\text { H3-8-16\% Rolling } \\
\text { H4->16\% Hilly \& Mountainous }\end{array}$ & FAO \\
\hline Soils & $\begin{array}{c}\text { H1 - Very Clayey } \\
\text { H2- Clayey } \\
\text { H3- Loam } \\
\text { H4- Sandy }\end{array}$ & \\
\hline Proximity to existing water points & $\begin{array}{c}\mathrm{H} 1->10 \mathrm{~km} \\
\mathrm{H} 2->6-10 \mathrm{~km} \\
\mathrm{H} 3->4-6 \mathrm{~km} \\
\mathrm{H} 4-0-4 \mathrm{~km} \\
\end{array}$ & $\begin{array}{l}\text { Experts within Kajiado, values based on village and grazing } \\
\text { route proximity. }\end{array}$ \\
\hline Proximity grazing routes & $\begin{array}{c}\mathrm{H} 1->10 \mathrm{~km} \\
\mathrm{H} 2->6-10 \mathrm{~km} \\
\mathrm{H} 3->4-6 \mathrm{~km} \\
\mathrm{H} 4-0-4 \mathrm{~km}\end{array}$ & See Proximity to villages criterion \\
\hline Pastures & $\begin{array}{c}\text { H1 -NDVI }(<=0.1) \\
\text { H2- NDVI }(>0.1-0.3) \\
\text { H3-NDVI }(>0.3-0.6) \\
\text { H4- }>\text { NDVI }(>0.6)\end{array}$ & Weier and Herring (2000) \\
\hline Proximity to villages & $\begin{array}{c}\mathrm{H} 1-0-4 \mathrm{~km} \\
\mathrm{H} 2-4-6 \mathrm{~km} \\
\mathrm{H} 3-6-10 \mathrm{~km} \\
\mathrm{H} 4->10 \mathrm{~km}\end{array}$ & Derived based on long-term average distances \\
\hline Agricultural \& urban areas & Exclusion Areas & $\begin{array}{l}\text { Agricultural areas are not for nomadic pastoralism; Urban } \\
\text { areas have good water supply with no pastoralists }\end{array}$ \\
\hline
\end{tabular}

\section{Results}

\subsection{Weighting}

A matrix for each respondent was formed to calculate the weights and the consistency ratio.

Comparison of the variables by the different group of residents was carried out. Fig.3 is a graph showing comparisons for the different element as rated by the selected experts.

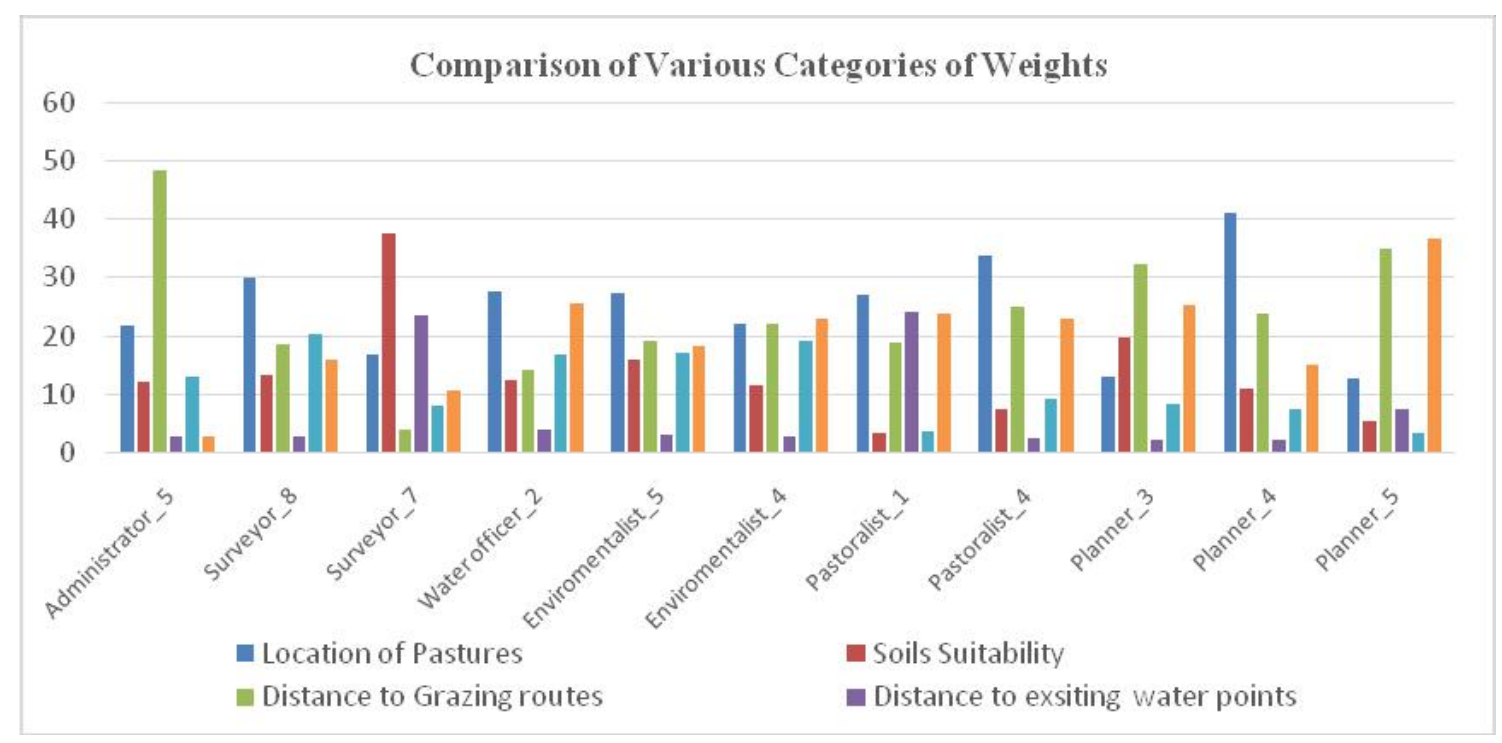

Figure 3. Comparison of weight categories

Through AHP, criteria weights were combined to get the options scores, thus determining a global score for each option and a consequent ranking. The global score for a given option was a weighted sum of the scores it obtained on all the criteria. Fig.4 below shows the weighted sum of the selected variables for this study. 


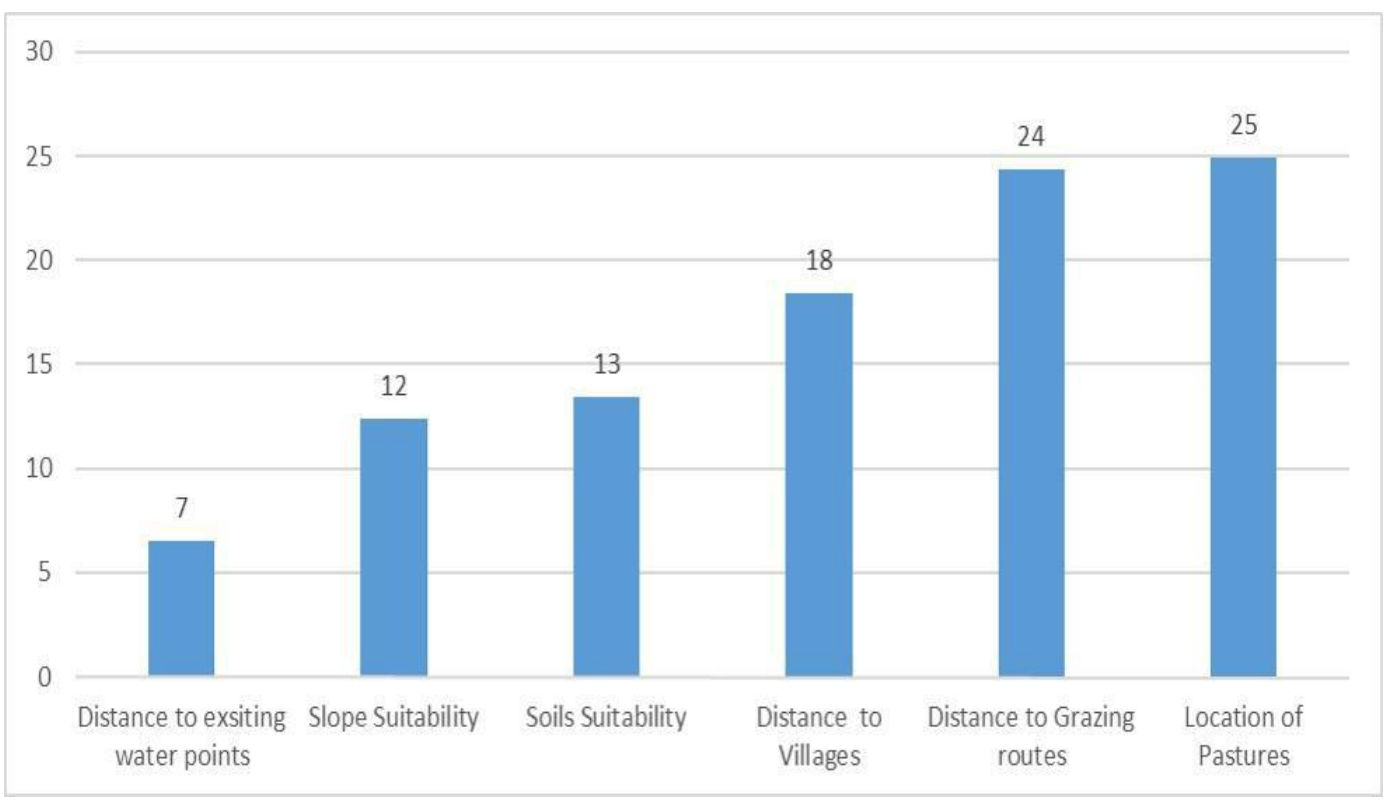

Figure 4. Average weight for variables

\subsection{Normalized Difference Vegetative Index (NDVI)}

Images for the years 1995, 2000, 2005 and 2015 were used forming four epochs. The images used were for the months of January to March because they are the driest months of the year and also cloud cover is low. The separate images were then averaged showing the condition of vegetation cover in Kajiado County. Fig. 5 shows the averaged NDVI map for the four years.

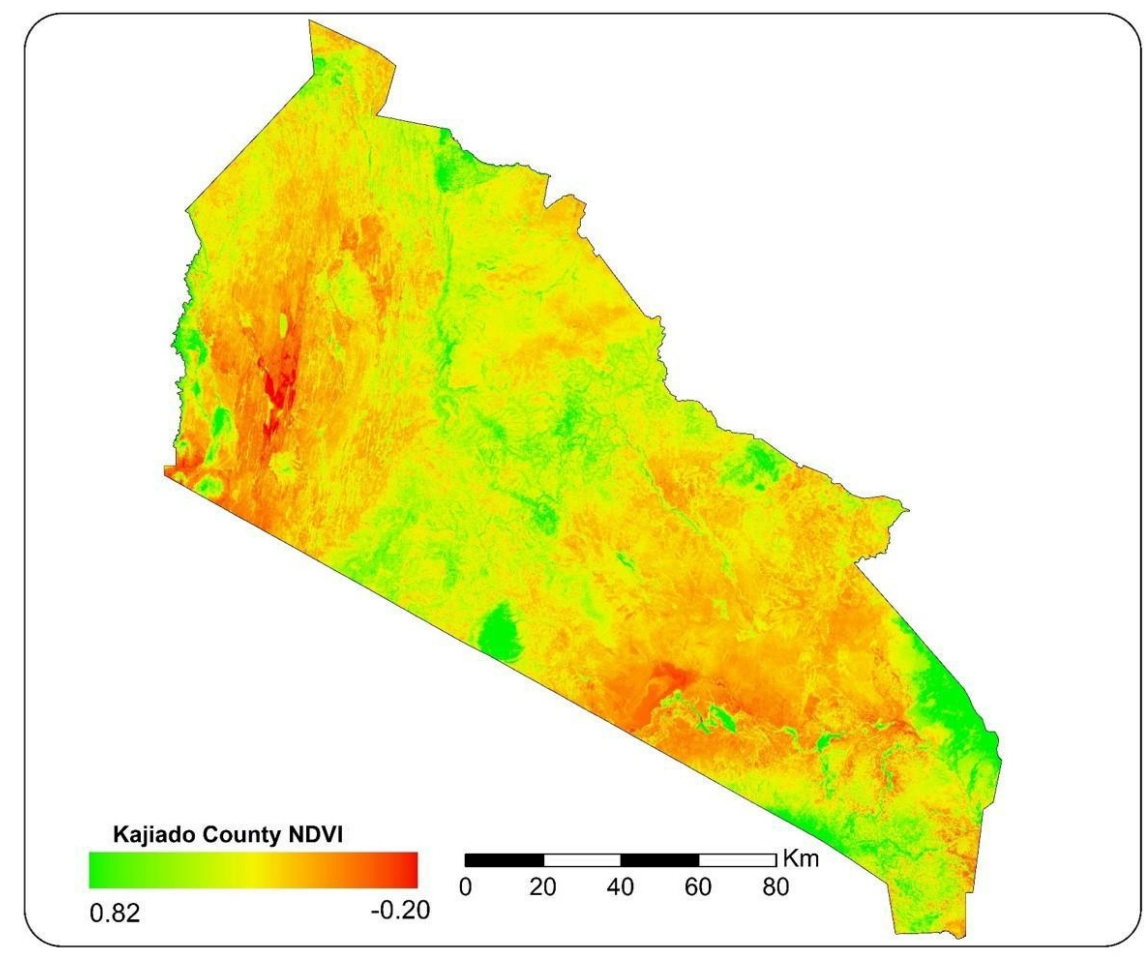

Figure 5. Averaged NDVI map

Data for the variables to be used in generating the suitability map was processed. This included generating maps showing; grazing pastures, soils, distance to grazing routes, distance to existing water points, slope, and villages of Kajiado County.

The multi-criteria analysis was done allowing the alternative elements to be ranked in order of suitability. With common scale and coordinate, the maps for the different elements were combined, and analysis was done. The resulting map was a suitability map. Fig. 6 below shows areas that are very highly suitable, highly suitable, moderately suitable and that are not suitable. 


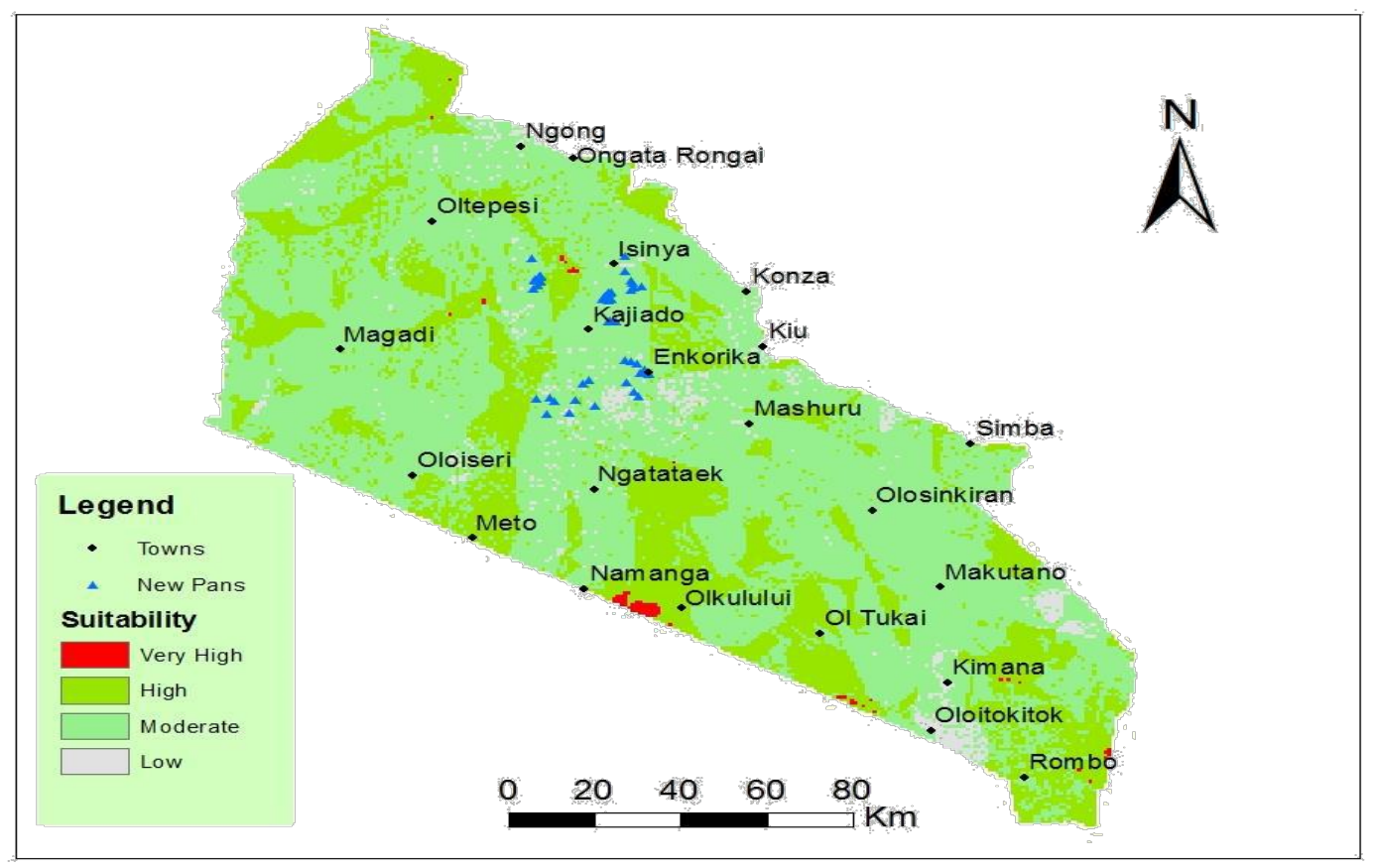

Figure 6. Suitability map

\section{Discussion}

The results from averaging the weighting variables as shown in Fig. 4 shows that distance to grazing routes and location of pastures was given the most importance. Distance to existing water points and slope suitability was given the least importance

The averaged NDVI map shown in Fig. 5 shows that vegetation cover is very scarce. As per the map, the NDVI for the most part of the county's land mass is approximately 0.5 . This can be concluded to mean that grazing pastures for the livestock during the dry spell is very scarce. As a result, the pastoralists have to walk for longer distance in search of food for the livestock. With most of the time spent in search of pastures, they have little or no time in satisfying other basic need and the outcome is a growth in poverty and as a result become poor.

From the map in Fig. 6, it shows that the very high suitable area is very small in the county and is near Namanga, Loitokitok and Kipeto. The majority of the area is moderately suitable with the lesser percentage being highly suitable. The area that is not suitable is very little which means water pans can be built for the most of the county. The suitability map also indicates that most of the new water pans excavated in 2015 lie on the moderately suitable areas. In summary, with areas that are very highly suitable and highly suitable the county government can use water pans to supply water to the most part the county.

\section{Conclusions}

The paper concludes that most of the new water pans that were established in 2015 lie on the moderately suitable areas.
The decision to build the water pans can be attributed to lack of GIS analysis and spatial modeling of data which resulted in uninformed decision making. Such a study can be concluded to be very necessary while determining the suitable location for building water pans. It should therefore, be used a guide by the County Government in its efforts to provide sustainable water pans to its people.

Without its limitation, it is observed that the results of this study can be improved. It can be improved by the use of updated and recent dataset to ensure that there are no conflicting interests in the study that are not shown by the available GIS research data. By carrying out the ground survey, smaller details that were not discernable within the data resolution can be taken into account. Also, wide research can be done by involving more parties in filling out the questionnaires.

\section{Acknowledgements}

I would like to express my deepest appreciation to all those who provided me the possibility to complete this report. A special gratitude to my project supervisor, Dr. Mark Boitt, whose contribution in motivating suggestions and encouragement, helped me to coordinate my project especially in writing this journal.

Furthermore, I would also like to acknowledge with much appreciation the crucial role of the staff of Department of Geomatic Engineering and Geospatial Information System, who gave the permission to use all required equipment and the necessary materials to complete the task. I have to appreciate the guidance given by other supervisor's as well as the panels especially in our project presentation that has improved our presentation skills thanks to their comment and 
advice. Last but not least, appreciation to my husband Jeremiah who supported me both financially and technically throughout the project.

\section{REFERENCES}

[1] UN-Water/Africa, "The Africa Water Vision for 2025: Equitable and Sustainable Use of Water for Socioeconomic Development."

[2] UNESCO, Managing Water under Uncertainty and Risk, The United Nations World Water Development Report 4 Volume 1,2012 .

[3] WWAP (United Nations World Water Assessment Programme), The United Nations World Water Development Report 2014: Water and Energy, Paris, 2014.

[4] Ministry of Planning and the National Development Republic of Kenya, Millenium Development Goals in Kenya Needs \& Costs, Nairobi, 2005

[5] UNESCO PRESS, Strategic groundwater reserves found in Northern Kenya, Media Services, 2013. [Online]. $\mathrm{http} / / / \mathrm{www}$.unesco.org/new/en/media-services/singleview/ne ws/strategic_groundwater_reserves_found in northern_ken ya/. VYGqtfmqqko. [Accessed: 17-Jun-2015].

[6] T. Kang'ethe and G. Kimathi, Kajiado County: 2013 long spots of the rain food security assessment report, 2014.

[7] County Government of Kajiado, County Integrated Development Plan 2013-2017, 2013.

[8] N. Gomes, Access to water, pastoral resource management, and pastoralists' livelihoods, LSP Working Paper 26, 2006.

[9] I. A. Jamali, U. Mörtberg, B. Olofsson, and M. Shafique, A Spatial Multi-Criteria Analysis Approach for Locating Suitable Sites for Construction of Subsurface Dams in Northern Pakistan, Water Resour. Manag., vol. 28, no. 14, pp. 5157-5174, 2014.

[10] Fratkin E. East African pastoralism in transition: Maasai, Boran, and Rendille cases. Afr Stud Rev.2001;44: 1-25. doi: $10.2307 / 525591$

[11] United Nations Development Programme. Combating Desertification in Kenya: Emerging lessons from Empowering Local Communities. Nairobi; 2013.

[12] Kirkbride M, Grahn R. Survival of the fittest: Pastoralism and climate change in East Africa. 2008.

[13] National Drought Management Authority Kajiado County, Drought Monitoring Bulletin, June 2013, 2013.
[14] National Drought Mangement Authority Kajiado County Kenya, Early Warning Bulletin for January 2015, 2015.

[15] A. Rikalovic, I. Cosic, and D. Lazarevic, GIS-based multi-criteria analysis for industrial site selection, Procedia Eng., vol. 69, pp. 1054-1063, 2014.

[16] A. K. Antonakos, K. S. Voudouris, and N. I. Lambrakis, Site selection for drinking-water pumping boreholes using a fuzzy spatial decision support system in the Korinthia prefecture, SE Greece, Hydrogeol. J., 2014.

[17] Zhu, Healey, and Aspinall, A Knowledge-Based Systems Approach to Design of Spatial Decision Support Systems for Environmental Management, Environ. Manage., vol. 22, no. 1, pp. 35-48, Jan. 1998.

[18] N. S. Al-Daghastania and K. J. Al-Maitahb, Preliminary Location of the Groundwater Wells Using Gis Techniques: a Case Study of the Hrh Tasneem Bint Ghazi for Technology Research Station: Proceedings of the ISPRS Commission VII Symposium "Remote Sensing: From Pixels to Processes," 2006, pp. 1-7.

[19] R. Carter, J. Chilton, K. Danert, and A. Olschewski, Siting of Drilled Water Wells: A Guide for Project Managers, 2010.

[20] World Agroforestry Centre and World Agroforestry Centre, Water from ponds, pans and dams: A manual on planning, design, construction and maintenance.

[21] T. L. Saaty and M. S. Özdemir, "How Many Judges Should There Be in a Group ?," Ann. Data Sci., vol. 1, no. 3-4, pp. 359-368, 2014.

[22] Thomas L. Saaty, Decision making with the analytic hierarchy process, Int. J. Services Sciences, Vol. 1, No. 1, 2008

[23] P. M. Macharia, C. N. Mundia, and M. W. Wathuo, "Experts' Responses Comparison in a GIS-AHP Oil Pipeline Route Optimization: A Statistical Approach," Am. J. Geogr. Inf. Syst., vol. 4, no. 2, pp. 53-63, 2015.

[24] Henik Joshua John, Utilizing NDVI and remote sensing data to identify spatial variability in plant stress as influenced by management, Iowa State University, Ames, Iowa, 2012

[25] He Yin, Thomas Udelhoven, Rasmus Fensholt, Dirk Pflugmacher, and Patrick Hostert, How Normalized Difference Vegetation Index (NDVI) Trends from Advanced Very High-Resolution Radiometer (AVHRR) and Système Probatoire d'Observation de la Terre VEGETATION (SPOT VGT) Time Series Differ in Agricultural Areas: An Inner Mongolian Case Study, Remote Sens. 2012, 4, 3364-3389; doi: $10.3390 /$ rs 4113364

[26] P. M. Macharia and C. N. Mundia, "GIS Analysis and Spatial Modelling for Optimal Oil Pipeline Route Location. A Case Study of Proposed Isiolo Nakuru Pipeline Route," Int. J. Sci. Res., vol. 3, no. 12, pp. 1227-1231, 2014. 